Cahiers $d u$ MONDE RUSSE

\section{Cahiers du monde russe}

Russie - Empire russe - Union soviétique et États indépendants

$51 / 4 \mid 2010$

Sciences humaines et sociales en Russie à l'Âge d'argent

\title{
Niccolò Pianciola, Stalinismo di frontiera
}

\section{Alessandro Stanziani}

\section{(2) OpenEdition}

Journals

Édition électronique

URL : https://journals.openedition.org/monderusse/7439

DOI : 10.4000/monderusse.7439

ISSN : 1777-5388

Éditeur

Éditions de l'EHESS

Édition imprimée

Date de publication : 25 novembre 2010

Pagination : 806-807

ISBN : 978-2-7132-2316-7

ISSN : $1252-6576$

Référence électronique

Alessandro Stanziani, « Niccolò Pianciola, Stalinismo di frontiera », Cahiers du monde russe [En ligne], 51/4 | 2010, mis en ligne le 09 décembre 2011, consulté le 03 septembre 2022. URL : http://

journals.openedition.org/monderusse/7439; DOl : https://doi.org/10.4000/monderusse.7439

Ce document a été généré automatiquement le 3 septembre 2022.

Tous droits réservés 


\title{
Niccolò Pianciola, Stalinismo di frontiera
}

\author{
Alessandro Stanziani
}

\section{RÉFÉRENCE}

Niccolš PIANCIOLA, Stalinismo di frontiera. Colonizzazione agricola, sterminio dei nomadi e costruzione statale in Asia centrale (1905-1936). Vicenza : Viella, 2009, $548 \mathrm{p}$.

1 Niccolò Pianciola est un jeune chercheur italien qui fait partie de cette nouvelle génération d'historiens s'efforçant, en Italie comme dans d'autres pays, d'étudier la construction soviétique dans sa dimension impériale et, si possible, de décloisonner la "soviétologie» des générations précédentes en l'arrachant à des jugements par trop définitifs sur le totalitarisme et sur un État tout-puissant. Ce bel ouvrage parvient à gagner le premier pari haut la main, le second peut-être un peu moins. L'auteur étudie en effet les relations entre État, paysans et bergers nomades au Kazakhstan au début des années 1930, plus précisément la politique stalinienne de sédentarisation et de collectivisation forcées, accompagnée de disettes en bonne partie provoquées par le régime soviétique. En même temps, Pianciola inscrit cette politique dans une histoire plus longue de colonisation de ces régions menée par les autorités tsaristes dès la fin du $\mathrm{XIX}^{\mathrm{e}}$ siècle. En effet, l'émigration russe vers l'Asie centrale, le renforcement de l'appareil étatique dans cette nouvelle aire de colonisation et les réactions des populations locales interagissent tout au long de la période étudiée. Pianciola considère que ces tensions expriment un double processus de longue durée : conflits entre paysans et État, en Russie et en URSS, d'une part; construction de l'État (state building), de l'autre. Suivant cette perspective, la "dénomadisation » constitue une manifestation extrême du contrôle politique, social et économique des paysans par l'État tsariste, puis soviétique. Colonisation et génocide des populations autochtones accompagnent ce processus qui aurait ainsi deux points culminants : répression des révoltes kirghizes en 1916 et disette 
de 1931-1933. Dans les deux cas, l'État et les colons russes auraient procédé à une politique d'extermination consciente des populations locales.

2 Le premier chapitre décrit l'occupation des steppes et les premières années de colonisation jusqu'aux réformes de Stolypin. Le deuxième étudie les années de guerre et de révolution (1914-1920), tandis que le troisième met l'accent sur la politique bolchevique dite de "pacification ", comportant une tentative d'accorder davantage de pouvoir aux populations locales. Le quatrième chapitre détaille les conditions de vie socioéconomiques de la population kazakhe pendant les années 1920 ; le suivant analyse les relations entre les différentes ethnies ainsi que la politique soviétique en matière de redistribution de ressources agricoles et d'accès aux postes de pouvoir, sans oublier les conflits éventuels dans tous ces domaines. Le sixième chapitre annonce le tournant de la fin des années 1920, lorsque sont mises en place les nouvelles orientations politiques qui aboutiront à la collectivisation et à la sédentarisation forcées du début des années 1930 . Le septième prend acte de ces deux phénomènes en analysant les réactions de la population, tandis que le dernier détaille la disette des années 1931-1933, que l'auteur considère comme une conséquence directe de la politique colonisatrice.

3 À la différence d'autres constructions impériales, les colons russes en Asie centrale n'acquerront jamais le contrôle des institutions de l'Empire, ni d'ailleurs de la terre qui demeure propriété de l'État. Cependant, l'explosion des révoltes en Asie centrale trouve moins son origine dans cette politique que dans l'enrôlement forcé des nomades dans l'armée tsariste lors de la Première Guerre mondiale. La répression est dès lors un fait essentiellement militaire, dans lequel, du moins initialement, les colons russes jouent un rôle limité. Les premières années du régime soviétique visent précisément à désamorcer ces conflits entre colons et populations locales et à intégrer ces dernières dans l'appareil administratif étatique. Cependant, vers la fin des années 1920, un nouveau virage a lieu et les Soviétiques procèdent à une colonisation massive et violente. Selon Pianciola, cette dernière stratégie n'a aucune rationalité modernisatrice sinon celle d'extraire le maximum de ressources de la population locale et de la contrôler sur le plan politique.

4 À une grande complexité de l'analyse et des conclusions, qui témoigne d'une maturité surprenante pour un auteur aussi jeune, s'ajoute l'usage de sources multiples, dans plusieurs langues et dont la production est constamment problématisée. Ainsi, Pianciola a recours à trois archives centrales principales : GARF (archives de la révolution), RGASPI (archives du parti) et RGVA (archives militaires), auxquelles s'ajoutent les archives centrales, celles du président et celles du parti au Kazakhstan, ainsi que les archives centrales d'Ouzbékistan. Les archives locales d'Almaty et de Shimkent complètent cette documentation impressionnante.

5 En conclusion, il s'agit d'un ouvrage important pour l'ensemble de l'historiographie sur la politique soviétique en Asie centrale. On ne peut qu'attendre avec impatience les travaux à venir de ce chercheur hautement prometteur. 